\title{
The influence of coating super-hydrophobic carbon nanomaterials on the performance of membrane distillation
}

\author{
Mustafa M. Aljumaily ${ }^{1} \cdot$ Haiyam M. Alayan ${ }^{2} \cdot$ Ahmed A. Mohammed $^{3} \cdot$ Mohammed A. Alsaadi $^{4} \cdot$ Qusay F. Alsalhy $^{2}$ (D) \\ Alberto Figoli ${ }^{5} \cdot$ Alessandra Criscuoli $^{5}$
}

Received: 13 April 2021 / Accepted: 22 December 2021 / Published online: 7 February 2022

(c) The Author(s) 2022

\begin{abstract}
Membrane distillation (MD), as a hybrid desalination technology with super-hydrophobic characteristics, has been emerging in the recent year. In this contest, the outstanding features of carbon-based nanomaterials have promising potential to contribute to the MD process evolution. This work presented an endeavor to impart the super-hydrophobic features of powder activated carbon (PAC) into poly(vinylidene fluoride-co-hexafluoropropylene) (PVDF-HFP) membranes for DCMD applications. The FTIR indicates that the CNM was successfully coated onto the PVDF-HFP membrane which leading to higher contact angle values (from $83^{\circ}$ to $124^{\circ}$, porosity $(45 \% 86.9 \%$ ) and water distillate flux at each increment in the PAC loading weigh. The novel coated membranes with $30 \mathrm{mg}$ CNM led to an enhancement of the permeate flux (higher fluxes were obtained at higher CNMs loading) presented fluxes around $77 \mathrm{~L} / \mathrm{m}^{2} . \mathrm{h}$ and exhibited a high salt rejection $(>99.9 \%)$ in most cases.
\end{abstract}

Keywords Super-hydrophobic $\cdot$ Carbon nanomaterials $\cdot$ Membrane $\cdot$ Desalination $\cdot$ Direct contact membrane distillation

\section{Introduction}

Membrane distillation (MD) is a separation process based on the vapor partial pressure difference across a hydrophobic membrane and is able to efficiently treat high saline water (P. Wang and Chung 2015). Only vapor molecules can pass through the porous membrane and the salt is concentrated at the feed side (Alkhudhiri et al. 2012). Direct contact membrane distillation is the most frequently utilized

Qusay F. Alsalhy

qusay_alsalhy@yahoo.com;

qusay.f.abdulhameed@uotechnology.edu.iq

1 Department of Civil Engineering, Al-Maarif University College, Al-Ramadi, Iraq

2 Membrane Technology Research Unit, Chemical Engineering Department, University of Technology-Iraq, Alsena'a Street No. 52, B. O. 35010, Baghdad 10066, Iraq

3 Career Development Center, University of Fallujah, Al-Fallujah, Iraq

4 National Chair of Materials Science and Metallurgy, University of Nizwa, Nizwa, Sultanate of Oman

5 Institute on Membrane Technology, National Research Council (ITM-CNR), 87030 Rende, CS, Italy configuration, where the feed of hot seawater is separated from the flood of cold fresh water due to the barrier of the hydrophobic membrane (Aljumaily et al. 2018a, b, c; Wang et al. 2008). To allow the flow of water vapor and to avoid the passage of liquid, it is imperative to employ a hydrophobic, porous, and thin membrane (Dumée et al. 2013). Nonetheless, this process is often limited by the lower permeate flux and its vulnerability to the processing circumstances, especially the salt solution temperature and concentration and low resistance to biofouling (Meng et al. 2014). For water purification to be energy-efficient and cost-effective, it is crucial to have membranes with high permeability and rejection, as well as good anti-biofouling properties (Lee et al. 2016). Membrane biofouling starts with a permanent bond and adhesion of one or more bacteria or other microorganisms to the membrane surface (Aljumaily et al. 2019). After that, the sessile cells grow rapidly and multiply, accompanied by feed water nutrients (Asadollahi et al. 2017).

A common approach to prevent biofouling and achieve high flux is to use carbon-based nanomaterials (CNMs) with a polymer, such as PVDF-HFP, to enhance the hydrophobicity of the composite membrane (Kochkodan and Hilal 2015; Rahman et al. 2017; Spasova et al. 2017). CNMs are the 
most favorable candidates because they have incomparable and exceptional mechanical, chemical, and thermal stability, as well as conductive and antibacterial properties (Alayan et al. 2017; AlOmar et al. 2017). The hydrophobic characteristics of any surface rely to a large extent on the chemical composition and geometrical features of the surface (Ma and Hill 2006; Zhu et al. 2014). With their exceptional features, $\mathrm{CNMs} /$ powder activated carbon (PAC) not only facilitate the development of the porosity, pore size, and hydrophobicity, but also form a resistance layer to prevent the growth of microorganisms (Kochkodan and Hilal 2015). CNMs/PAC are graphene sheets rolled up to form cylinders with nanoinner diameters (Zhao et al. 2013). CNMs/PAC have extraordinary mechanical, electrical, and thermal features, and recent studies found that they exhibit fast fluid flow through their interiors (Corry 2008). Therefore, the abovementioned characteristics have contributed to the strong interest in and attention to CNMs/PAC-based membranes of various structures (Alayan et al. 2020; Fornasiero et al. 2008).

This non-complicated technique can be applied for both dense and porous composite membranes. Small amount of active additives (CNMs/PAC) is required to modify one side only of the membrane surface by improving its hydrophobicity. Eventually, the bulk properties remain relatively unchanged. This technique is an economical choice taken in the account the fact that voids occupied $90 \%$ of the membrane volume.

\section{Materials and methods}

\section{Materials}

PAC, nickel (II) nitrate hexahydrate, acetone, acetylene $\left(\mathrm{C}_{2} \mathrm{H}_{2}\right)$, hydrogen $\left(\mathrm{H}_{2}\right)$, and nitrogen $\left(\mathrm{N}_{2}\right)$ were purchased from Sigma-Aldrich. CNMs/PAC were prepared based on the previously established optimum conditions and the method developed earlier (Aljumaily et al. 2018a, b, c). The membrane material, PVDF-co-HFP, was used as the matrix, with N-Methyl-2-pyrrolidone (NMP, $>99.5 \%$ ) as a solvent. All chemicals were of analytical grade and purchased from Sigma-Aldrich.

\section{Preparation of membranes}

The blank PVDF-HFP/NMP membranes were prepared by the phase inversion method. The ratio of polymer to solvent was 22:78 (wt \%/wt \%). A magnetic stirrer at $400 \mathrm{rpm}$ was used overnight to assure homogeneity of the mixture. The prepared polymer solution was cast (with a slot depth of $250 \mu \mathrm{m}$ ) into a thin film on a clean glass plate fixed on a casting machine at room temperature, and then exposed to air for 30-60 s. The thin film was immersed in distilled water along with the glass plate until a wet film floated to the water's surface. The membrane was rinsed again with fresh distilled water for $24 \mathrm{~h}$ to complete the removal of the solvent residues. The membranes were subsequently left at room temperature to dry before further use.

Super-hydrophobic CNMs/PAC, used as a coated material, was grown by chemical vapor deposition (CVD) using an established method, and it displayed external diameters and lengths of $23-65 \mathrm{~nm}$ and $150-250 \mathrm{~nm}$, respectively (Aljumaily et al. 2018). To attain consistent suspensions, the CNMs/PAC were detached in a diagnostic and analytic propan-2-ol and sonicated twice for $15 \mathrm{~min}$ at $170 \mathrm{~W}$. In the static analytical cell, the membrane was fixed between the upper and lower chamber. The upper chamber was filled with CNMs/PAC dispersed in propan-2-ol and linked to a nitrogen $\left(\mathrm{N}_{2}\right)$ cylinder that produced less than 2.5 bar pressure (Rácz et al. 2014). However, the lower chamber was attached to a digital flow meter to determine the gas when it passed through the membrane, as displayed in Fig. 1. The 60-mm wide pure PVDF-HFP sample was set $10 \mathrm{~cm}$ from the top. Moreover, the feed side of the sample was exposed to a nitrogen process pressure of $1.5 \times 10^{-5} \mathrm{SI}$ for $10 \mathrm{~min}$ at room temperature. The liquid flowed through the membrane after flooding the pores. Additionally, the solvent passed through the membrane while the $\mathrm{CNMs} / \mathrm{PAC}$ were trapped inside the pores. A vacuum oven (at $80{ }^{\circ} \mathrm{C}$ and $-20 \mathrm{kPa}$ ) dried the sample overnight to produce a coated membrane that could form a self-supporting PVDF-HFP composite when it was peeled off.

\section{FTIR analysis}

Attenuated total reflection-Fourier transform infrared spectroscopy (ATR-FTIR) was used to test the functional groups of the composite membrane to study the incorporation of

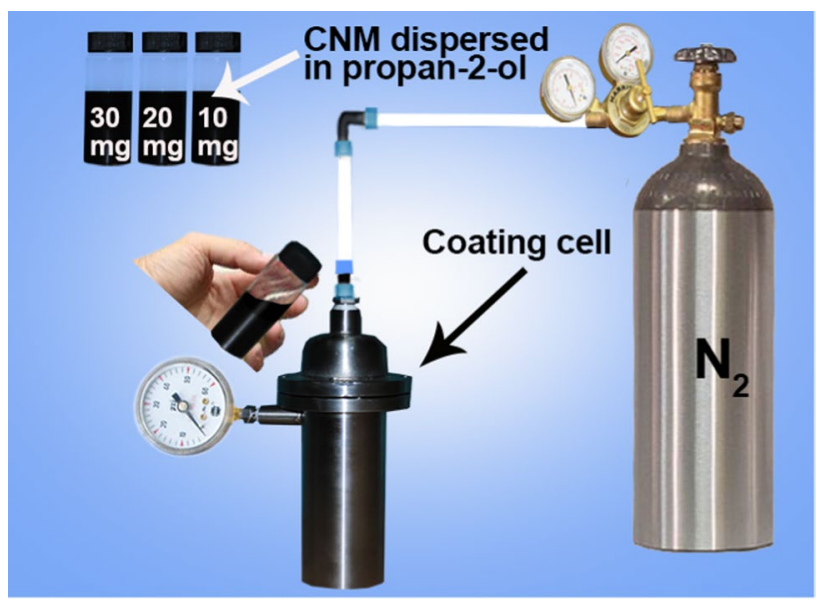

Fig. 1 Coating cell using the liquid entry pressure method 
$\mathrm{CNM}$ /PAC, and the spectra were recorded on a Nicolet ${ }^{\mathrm{TM}}$ $510 \mathrm{P}$ spectrometer. The wavelengths were recorded and ranged from 4000 to $500 \mathrm{~cm}^{-1}$.

\section{SEM and porosity measurements}

The prepared composite membranes were subjected to scanning electron microscopy (SEM) to define their type from the structure, using a SEM from JEOL JSM-5510 (JEOL Ltd., Japan). The composite membrane samples $\left(1 \mathrm{~cm}^{2}\right)$ were prepared by fracturing them in liquid nitrogen before securing them by SEM analysis. Membranes were coated with a thin layer of platinum.

The porosity (\%) of the prepared composite membrane was determined using the following equation (Alsalhy et al. 2013):

$\varepsilon(\%)=\frac{\rho_{m}}{\rho_{p}} \times 100$

where $\rho_{m}$ is the membrane density $\left(\mathrm{g} / \mathrm{cm}^{3}\right), \rho_{p}$ is the density of the polymer $\left(\mathrm{g} / \mathrm{cm}^{3}\right)$. The density of the PVDF-HFP was $1.78 \mathrm{~g} / \mathrm{cm}^{3}$.

\section{Contact angle measurement}

The measurement of the membrane surface was calculated using the $\mathrm{CA}$, which was determined by placing a water drop onto each glass microscope slide, which was then covered with double-sided adhesive tape, with the composite membrane placed on the top. A goniometer PG7 from Fibro System with $4 \mu \mathrm{L}$ drops was utilized for the sake of establishing the contact angle with deionized water. Each measurement was made in triplicate, and the average value was adopted.

\section{DCMD process}

In DCMD, the pressure difference of the water vapor in a membrane, which is hydrophobic and porous, stimulates the evaporation of water from a hot stream. Moreover, it facilitates the circulation and transmission of water vapor through the membrane, in addition to its condensation in the cold permeate, as shown in Fig. 2. The coated PVDF-HFP was tested in a circular module, with a diameter of $4.3 \mathrm{~cm}$. The tests were carried out in a counterflow current with an exposure at various feed temperatures. By dissolving $35 \mathrm{~g}$ of $\mathrm{NaCl}$ in $1 \mathrm{~L}$ of double-distilled water, the saltwater sample was prepared with its density resembling raw sea/ocean water. The concentration of both the feed and the permeate was measured using a conductivity and TDS meter (Extech, Malaysia). The salt rejection was calculated using Eq. 2:

$\operatorname{Rejection}(\%)=\left[1-\left(C_{p c} / C_{f c}\right)\right] \times 100$

where $C_{p c}$ and $C_{f_{c}}$ are the permeate and the feed concentration, respectively.

\section{Results and discussion}

\section{FT-IR analysis}

The functional groups of the composite membrane and PVDF-HFP were analyzed by FTIR, as shown in Fig. 3. A minor prevalence of a crystalline phase was observed in the PVDF-HFP membrane based on the existence of transmittance peaks at $528,614,760,795,840,876$, and $973 \mathrm{~cm}^{-1}$. However, peaks at 974, 1070, 1180, 1280, and 1400 can be attributed to the polymer/solvent NMP interactions (Fadhil et al. 2016). A peak for PVDF-HFP/CNMs/PAC was observed at $1660 \mathrm{~cm}^{-1}$, owing to $\mathrm{C}=\mathrm{O}$ stretching vibrations. Accordingly, this result indicates that the CNM/PAC was successfully coated onto the PVDF-HFP material.

\section{SEM and porosity}

SEM was used to examine the changes in the composite membrane morphology due to the addition of CNMs/PAC. Figure $4 \mathrm{a}$ and $\mathrm{b}$ represents the SEM images for the top surface and cross sections of the composite membranes.

Fig. 2 Direct contact membrane distillation system

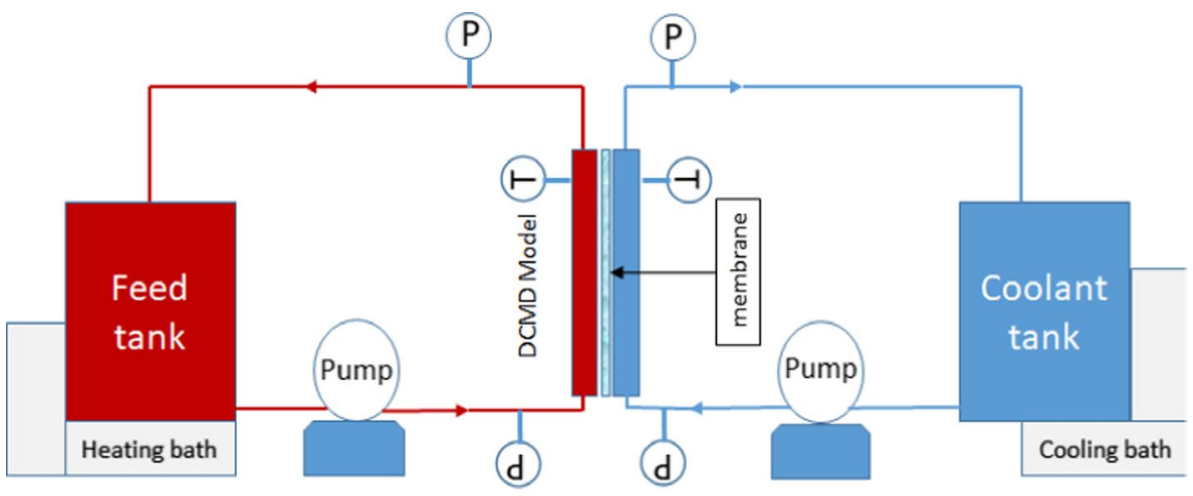




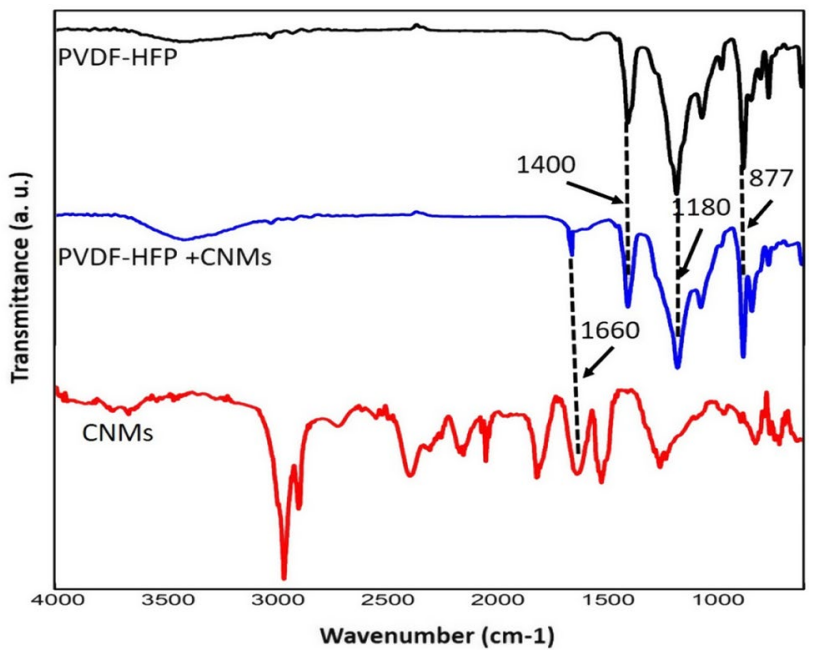

Fig. 3 FT-IR spectra of neat PVDF-HFP and composite membranes

A finger-like structure was observed in the cross section images of the membrane prepared from neat PVDF-HFP as shown in (c and d). The high-resolution SEM imaging showed that a thin, continuous, and porous film had formed at the surface because of the PVDF-HFP coating, as seen in Fig. 4a. This formation revealed the results after coating the CNMs composite, which was displayed in high magnification SEM. The images show little to no blockages or any massive transformations in the polymer agglomerates on the membrane surface, which seems not to be affected.

The overall porosity was determined by the gravimetric method which provide a porosity of $75 \%$ for the sample in Fig. 4a. The figure shows that the worm-like tube nickel nanoparticles with a cross section diameter and length of around 35 and $100 \mathrm{~nm}$ which impregnated with the CNM/ PAC. It was observed and reported that the presence of CNMs in the polymeric matrix led to an increase in materials crystallinity and effect the structural and thermal properties of the fabricated membrane (Pandele et al. 2020).

An increased loading of the CNMs/PAC from 10 to $30 \mathrm{mg}$ resulted in an increasing of the porosity of the composite membranes from 45.3 to $86.94 \%$, as shown in Fig. 5. There was a highly significant effect of the CNMs/PAC loading on the porosity of the composite membrane. The increment of the porosity in the PVDF-HFP/CNMs/PAC composite membranes was closely related to the prevalence and interactions of the $\mathrm{CNMs} / \mathrm{PAC}$ with the polymer solution, which impacted the NMP/water exchange rate throughout the formation of the membrane, causing a porous surface to form.

\section{Contact angle measurements of the composite membrane}

The contact angle (CA) is one of the key evaluation parameters of the membrane and is considered a valuable indicator of the ability of water to penetrate the membrane wall. A potential problem with the MD process is the risk of membrane pore wetting, which may decrease the performance of the separation and flux of the permeate. In an MD process, the membrane should be hydrophobic to prevent the water from penetrating the wall, so only water vapor can diffuse through the membrane body. Therefore, to develop and improve the membrane's hydrophobicity (which enhances the membrane performance), CNMs/PAC with a highly hydrophobic character were prepared by the method
Fig. 4 (a) membrane after coating by $\mathrm{CNM} / \mathrm{PAC}$, (b) cross section, (c) top, showing the finger-like structure, and (d) bottom, showing the spongelike structure
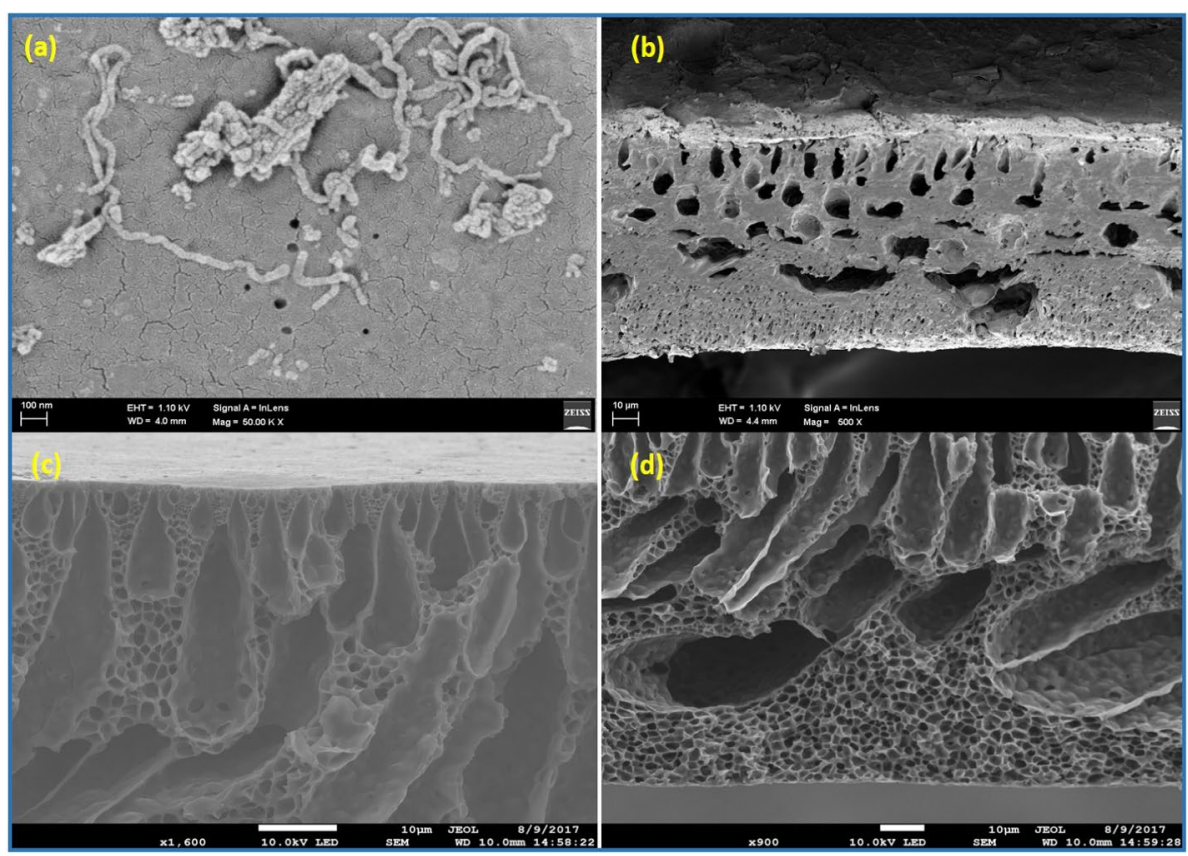


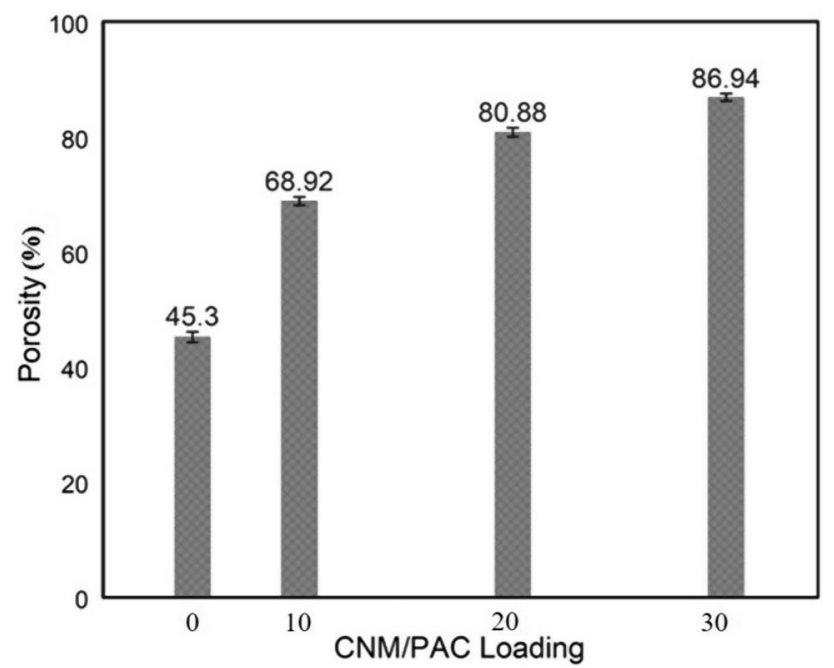

Fig. 5 Effect of CNMs/PAC loading on the porosity of the composite membranes

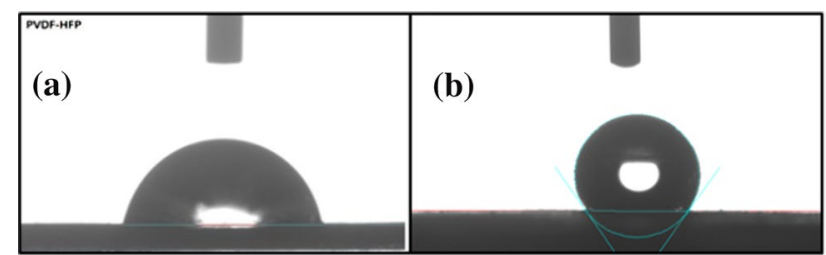

Fig. 6 (a) contact angle of PVDF-HFP and (b) CA of composite membrane (30-CNM/PAC)

Table 1 The result of contact angle after increase in the CNMs/PAC loading

\begin{tabular}{lc}
\hline Membrane & Contact Angle $\left(^{\circ}\right)$ \\
\hline pristine PVDF-HFP & $90.1^{\circ}$ \\
PVDF-HFP + 10CNM & $83.6^{\circ}$ \\
PVDF-HFP+20CNM & $113.3^{\circ}$ \\
PVDF-HFP+30CNM & $124.1^{\circ}$ \\
\hline
\end{tabular}

mentioned above and added to the casting solution of the polymer solution with various loadings (i.e., 10, 20, and 30 $\mathrm{mg}$ ). Figure 6 presents the result of the CA for the membranes prepared from various $\mathrm{CNMs} / \mathrm{PAC}$ loadings in the casting solution. The CA of PVDF-HFP/CNMs improved from 83 to $124^{\circ}$ with an increase in the $\mathrm{CNMs} / \mathrm{PAC}$ loading as shown in Table 1.

The hydrophobicity strongly depends on different points the fabrication process, the functional groups and the morphology of the membrane. The increase in the CA indicates that the hydrophobic CNMs/PAC can improve the hydrophobicity of the membrane surface relative to the pristine PVDF-HFP, for which the CA was reported to be $90.1^{\circ} \pm 1.7^{\circ}$

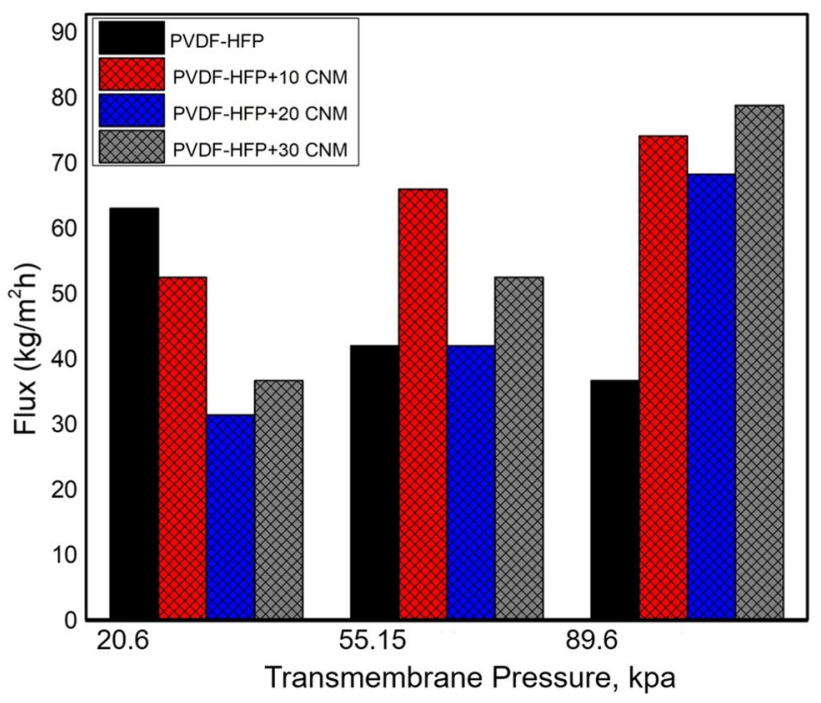

Fig. 7 Flux of the membranes by water pressure difference across the membrane

(Xie et al. 2014). The CA of the composite membrane increased by increasing the hydrophobic CNMs/PAC loading to the membrane. The observed results are attributed to the effect of CNMs/PAC coating. The $\mathrm{CNMs} / \mathrm{PAC}$ cover the surface uniformly, which increases the roughness of the composite membrane and provides a good enhancement of the membrane hydrophobicity. The roughness generates a larger CA, which implies a higher hydrophobicity.

\section{Performance of DCMD with PVDF-HFP/CNMs/PAC membranes}

There was a linear rise in the membranes' flux along with the water vapor pressure gradient, as displayed in Fig. 7. To compare the PVDF-HFP membranes of different CNMs/ PAC loading, the most appropriate method was the slope of the best-fit line (in $\mathrm{kg} / \mathrm{m}^{2} \mathrm{~h}$ pa). The results in Fig. 7 show the difference between the CNM/PAC-coated membranes and the uncoated PVDF-HFP, as the former proved to have a higher flux compared with other studies, as shown in Table 2. However, the latter presented $0.9 \mu \mathrm{m}$ as a higher average of pore size distributions. The higher permeability and other features of salt rejection ostensibly resulted from the membrane's varied structure and its higher porosity. In the coated membrane, the thin hydrophobic layer of the composite porous membrane was responsible for mass transport in distillation (i.e., a small path length between the hot and the cold liquid/vapor interfaces formed at both sides of the hydrophobic thin top-layer of the membrane), which was not true of the uncoated membrane.

The introduction of CNMs/PAC on the membrane surface played a positive role in the hydrophobicity 
Table 2 DCMD flux in the present study and that reported in selected literature for carbon nanomaterial membranes

\begin{tabular}{|c|c|c|c|c|c|c|c|c|}
\hline Composite Membrane & $\mathrm{CA}\left({ }^{\circ}\right)$ & LEP (bar) & pore size $(\mu \mathrm{m})$ & Porosity (\%) & $\begin{array}{l}\text { Salt } \\
\text { Rejection } \\
(\%)\end{array}$ & $\begin{array}{l}\text { Feed Tem- } \\
\text { perature } \\
\left({ }^{\circ} \mathrm{C}\right)\end{array}$ & $\begin{array}{l}\text { Water } \\
\text { Flux }(\mathrm{kg} / \\
\left.\mathrm{m}^{2} \mathrm{~h}\right)\end{array}$ & Ref. \\
\hline $\begin{array}{l}\text { Nanofiber PVDF- } \\
\text { HFP + CNT }\end{array}$ & 150 & 0.6 & - & 90 & 99 & $55-75$ & 36 & Dumée et al. (2010) \\
\hline Self-supporting CNT & 113 & 0.55 & 0.9 & - & - & $40-60$ & 12 & Lee et al. (2017) \\
\hline $\begin{array}{l}\text { Carbon nanotube bucky } \\
\text { paper membranes }\end{array}$ & 140 & 1.4 & - & - & 96.5 & 85 & 10 & Dumée et al. (2011) \\
\hline Nanofiber PVDF-HFP & 125 & 1.9 & 0.26 & 58 & 98 & 68 & 22 & Lalia et al. (2013) \\
\hline $\begin{array}{l}\text { Nano carbon mate- } \\
\text { rial + PVDF-HFP }\end{array}$ & 120 & - & 0.55 & 93 & 99.9 & 65 & 102 & $\begin{array}{l}\text { Aljumaily et al. (2018a, } \\
\text { b, c) }\end{array}$ \\
\hline $\begin{array}{l}\text { Carbon nanomate- } \\
\text { rial + PVDF-HFP }\end{array}$ & 133 & - & 0.4 & 86 & 99.9 & 55 & 16 & Aljumaily et al. (2019) \\
\hline $\begin{array}{l}\text { Multi-walled carbon nano- } \\
\text { tube + PVDF }\end{array}$ & 116 & - & 0.22 & 90 & 98.6 & - & 9.5 & Silva et al. (2015) \\
\hline
\end{tabular}

enhancement by decreasing the membrane surface free energy. The decrease in pore size was due to the partial filling of the surface pores of the membrane by the self-assembled layer comprised of CNMs/PAC, which enhanced the liquid entry pressure (LEP) of the hydrophilic porous membranes. The increased loading of the CNMs/PAC increased the water flux as more hydrophobic surfaces formed for the easy transport of water vapors without wetting. Also, the CNMs/PAC loading increased the membrane's total vapor evaporation area (due to the higher porosity), thereby increasing the water flux.

The higher value of the LEP of the water for the coated membranes indicated the increased transmembrane pressure across the membrane due to the reduced pore size after the surface coating. The permeate flux of all the coated membranes was much higher than that of the uncoated membrane. Generally, pore size reduction has an adverse effect on the flux, but the increased porosity of the coated membranes had a dominant effect in determining the membrane flux compared to the decreased pore size.

The water flux of all the membranes increased as the temperature rose due to the increased vapor pressure of seawater as a main driving force of the MD process (Aljumaily et al. 2019). In the MD process, the seawater directly contacted the surface of the neat PVDF/HFP membrane, which wet the pores. Trapped seawater can reduce the effective liquid evaporation area and cause flux reduction. However, the incorporation of CNMs/PAC into the PVDF/ HFP membrane matrix tends to improve both the pore-wetting resistance and the evaporation area, which eventually increases the membrane flux. CNMs/PAC additives incorporate a fine scale alteration that modifies the surface to enhance the turbulence and decreases the surface tension of the liquid, thus increasing the volatility of the liquid and reducing the temperature polarization. Thus, temperature polarization was reduced by inducing secondary flows in the fluid flowing inside the membrane.

On the other hand, the thin CNM/PAC coating on top of the membrane paved the way to a better performance. Water was prevented from wicking in the membrane by inducing a greater degree of hydrophobicity in the PVDFHFP. Eventually, the temperature polarization on feed sides of the membrane seemed to increase, as shown in Fig. 8. Additionally, the stabilization of the membrane's performance was achieved by the presence of PVDF-HFP, which augmented the membrane's stability; this also helps to reduce the danger of cracks forming.

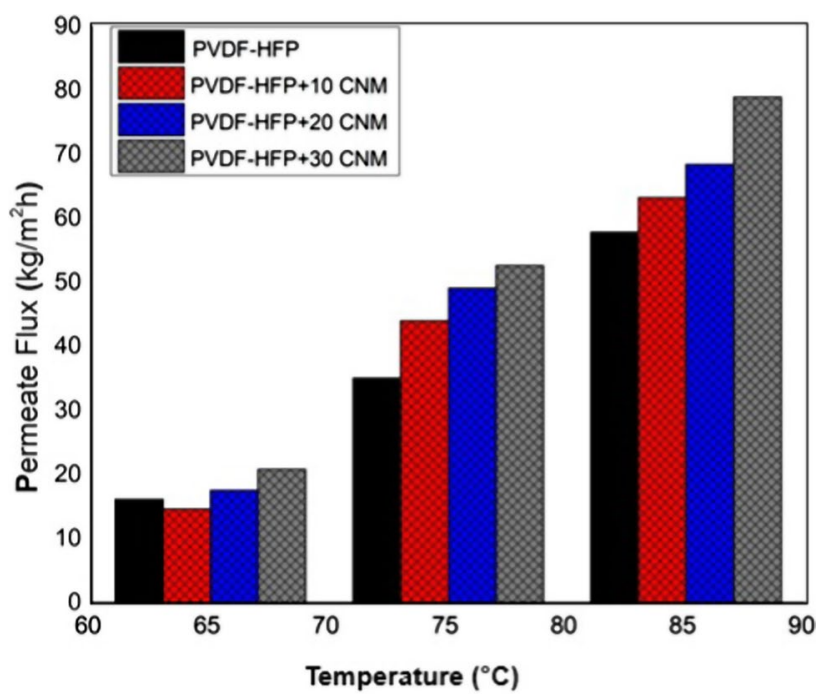

Fig. 8 Effect of the feed temperature on the water flux 


\section{Conclusions}

One disadvantage of the MD process is the risk of hydrophobic membrane pore wetting, which may decrease the performance of the separation and flux of the permeate. Composite flat membranes were fabricated using different amounts of CNMs/PAC coating (i.e., 10, 20, and $30 \mathrm{mg}$ ), using the liquid entry pressure method. The CA is one of the critical membrane parameters that indicates the ability of water to penetrate the membrane wall. The CA of the PVDF$\mathrm{HFP} / \mathrm{CNMs} / \mathrm{PAC}$ improved from 83 to $124^{\circ}$ by increasing the CNMs/PAC loading. The permeation flux of the PVDF$\mathrm{HFP} / \mathrm{CNM}$ s/PAC composite membranes was higher than that of the neat PVDF-HFP membrane and increased as the feed side temperature rose. In particular, at high temperatures, the composite membrane with $30 \mathrm{mg} \mathrm{CNMs} / \mathrm{PAC}$ coating presented fluxes around $77 \mathrm{~L} / \mathrm{m}^{2}$.h. During the experiment, the membranes' average salt rejection remained $>99.9 \%$. This study confirmed that as a result of the CNMs/PAC particles altering the PVDF-HFP, the membrane's performance under DCMD can be increased and developed.

Funding The author(s) received no specific funding for this work.

Data availability The data collected are a part of the Dr. Heyam experimental work and are provided with the best of its experiments.

\section{Declarations}

Conflict of interest The authors declare that they have no conflict of interest.

Consent for publication The authors agree to publish the paper based on the research conducted.

Consent to participate All the authors agreed to partake on the research conducted.

Ethical approval This article does not contain any studies with human or animal subjects.

Open Access This article is licensed under a Creative Commons Attribution 4.0 International License, which permits use, sharing, adaptation, distribution and reproduction in any medium or format, as long as you give appropriate credit to the original author(s) and the source, provide a link to the Creative Commons licence, and indicate if changes were made. The images or other third party material in this article are included in the article's Creative Commons licence, unless indicated otherwise in a credit line to the material. If material is not included in the article's Creative Commons licence and your intended use is not permitted by statutory regulation or exceeds the permitted use, you will need to obtain permission directly from the copyright holder. To view a copy of this licence, visit http://creativecommons.org/licenses/by/4.0/.

\section{References}

Alayan H, Aljumaily MM, Alsaadi MA, Hashim MA (2020) Probing the effect of gaseous hydrocarbon precursors on the adsorptive efficiency of synthesized carbon-based nanomaterials. The J Eng Res [TJER] 17(1):47-58

Alayan HM, Alsaadi MA, Abo-Hamad A, AlOmar MK, Aljumaily MM, Das R, Hashim MA (2017) Hybridizing carbon nanomaterial with powder activated carbon for an efficient removal of Bisphenol A from water: the optimum growth and adsorption conditions. Desalin Water Treat 95:128-143

Alsaadi A, Das R, Hamid SBA, AwanisHashim N, AlOmar MK, Alayan HM, Novikov M, Alsalhy QF, Hashim MA (2018a) Optimization of the synthesis of superhydrophobic carbon nanomaterials by chemical vapor deposition. Sci Rep 8(1):1-12

Alsalhy QF, Rashid KT, Ibrahim SS, Ghanim AH, Van der Bruggen B, Luis P, Zablouk M (2013) Poly(vinylidene fluoride-co-hexafluropropylene) (PVDF-co-HFP) hollow fiber membranes prepared from PVDF-co-HFP/PEG-600Mw/DMAC solution for membrane distillation. J Appl Polym sci 129:3304-3313

Aljumaily MM, Alsaadi MA, Hashim NA, Alsalhy QF, Das R, Mjalli F (2019) Embedded high-hydrophobic CNMs prepared by CVD technique with PVDF-co-HFP membrane for application in water desalination by DCMD. Desalin Water Treat 142:37-48

Aljumaily MM, Alsaadi MA, Hashim NA, Alsalhy QF, Mjalli FS, Atieh MA, Al-Harrasi A (2018b) PVDF-co-HFP/superhydrophobic acetylene-based nanocarbon hybrid membrane for seawater desalination via DCMD. Chem Eng Res Des 138:248-259

Aljumaily MM, Alsaadi MA, AwanisHashim N, Alsalhy QF, Mjalli FS, Atieh MA, Al-Harrasi A (2018c) PVDF-co-HFP/superhydrophobic acetylene-based nanocarbon hybrid membrane for seawater desalination via DCMD. Chem Eng Res Des 138:248-259

Alkhudhiri A, Darwish N, Hilal N (2012) Membrane distillation: a comprehensive review. Desalination 287:2-18

AlOmar MK, Alsaadi MA, Aljumaily MM, Akib S, Jassam TM, Hashim MA (2017) N, N-Diethylethanolammonium chloridebased DES-functionalized carbon nanotubes for arsenic removal from aqueous solution. Desalin Water Treat 74:163-173

Asadollahi M, Bastani D, Musavi SA (2017) Enhancement of surface properties and performance of reverse osmosis membranes after surface modification: a review. Desalination 420:330-383

Corry B (2008) Designing carbon nanotube membranes for efficient water desalination. J Phys Chem B 112(5):1427-1434

Dumée L, Germain V, Sears K, Schütz J, Finn N, Duke M, Gray S (2011) Enhanced durability and hydrophobicity of carbon nanotube bucky paper membranes in membrane distillation. J Membr Sci 376(1-2):241-246

Dumée LF, Gray S, Duke M, Sears K, Schütz J, Finn N (2013) The role of membrane surface energy on direct contact membrane distillation performance. Desalination 323:22-30

Dumée LF, Sears K, Schütz J, Finn N, Huynh C, Hawkins S, Gray $S$ (2010) Characterization and evaluation of carbon nanotube Bucky-Paper membranes for direct contact membrane distillation. J Membr Sci 351(1-2):36-43

Fadhil S, Marino T, Makki HF, Alsalhy QF, Blefari S, Macedonio F, Figoli A (2016) Novel PVDF-HFP flat sheet membranes prepared by triethyl phosphate (TEP) solvent for direct contact membrane distillation. Chem Eng Process 102:16-26

Fornasiero F, Park HG, Holt JK, Stadermann M, Grigoropoulos CP, Noy A, Bakajin O (2008) Ion exclusion by sub-2-nm carbon nanotube pores. Proc Natl Acad Sci 105(45):17250-17255

Kochkodan V, Hilal N (2015) A comprehensive review on surface modified polymer membranes for biofouling mitigation. Desalination 356:187-207 
Lalia BS, Guillen-Burrieza E, Arafat HA, Hashaikeh R (2013) Fabrication and characterization of polyvinylidenefluoride-co-hexafluoropropylene (PVDF-HFP) electrospun membranes for direct contact membrane distillation. J Membr Sci 428:104-115

Lee A, Elam JW, Darling SB (2016) Membrane materials for water purification: design, development, and application. Environ Sci Water Res Technol 2(1):17-42

Lee J-G, Lee E-J, Jeong S, Guo J, An AK, Guo H, Ghaffour N (2017) Theoretical modeling and experimental validation of transport and separation properties of carbon nanotube electrospun membrane distillation. J Membr Sci 526:395-408

Ma M, Hill RM (2006) Superhydrophobic surfaces. Curr Opin Coll Interface Sci 11(4):193-202

Meng S, Ye Y, Mansouri J, Chen V (2014) Fouling and crystallisation behaviour of superhydrophobic nano-composite PVDF membranes in direct contact membrane distillation. J Membr Sci 463:102-112

Pandele AM, Serbanescu OS, Voicu SIJC (2020) Polysulfone composite membranes with carbonaceous structure. Syn Appl 10(7):609

Rácz G, Kerker S, Kovács Z, Vatai G, Ebrahimi M, Czermak P (2014) Theoretical and experimental approaches of liquid entry pressure determination in membrane distillation processes. Period Polytech Chem Eng 58(2):81

Rahman SA, Rashid KT, Alsalhy QF (2017) Improvement of PVDFco-HFP hollow fiber membranes for direct contact membrane distillation applications. Indian J SciTechnol, https://doi.org/10. 17485/ijst/2017/v10i7/111446

Silva TL, Morales-Torres S, Figueiredo JL, Silva AM (2015) Multiwalled carbon nanotube/PVDF blended membranes with spongeand finger-like pores for direct contact membrane distillation. Desalination 357:233-245
Spasova M, Manolova N, Markova N, Rashkov I (2017) Tuning the properties of PVDF or PVDF-HFP fibrous materials decorated with $\mathrm{ZnO}$ nanoparticles by applying electrospinning alone or in conjunction with electrospraying. Fibers Polym 18(4):649-657

Wang KY, Chung T-S, Gryta M (2008) Hydrophobic PVDF hollow fiber membranes with narrow pore size distribution and ultra-thin skin for the fresh water production through membrane distillation. Chem Eng Sci 63(9):2587-2594

Wang P, Chung T-S (2015) Recent advances in membrane distillation processes: Membrane development, configuration design and application exploring. J Membr Sci 474:39-56

Xie L, Huang X, Yang K, Li S, Jiang P (2014) "Grafting to" route to PVDF-HFP-GMA/BaTiO 3 nanocomposites with high dielectric constant and high thermal conductivity for energy storage and thermal management applications. J Mater Chem A 2(15):5244-5251

Zhao W, Nam SD, Pokhrel A, Gong J, Kim IJ (2013) Carbon nanotube synthesis and growth using zeolite by catalytic CVD and applications. J Korean Ceram Soc 50(1):1-17

Zhu L, Shi P, Xue J, Wang Y, Chen Q, Ding J, Wang Q (2014) Superhydrophobic stability of nanotube array surfaces under impact and static forces. ACS Appl Mater Interfaces 6(11):8073-8079. https://doi.org/10.1021/am500261c

Publisher's Note Springer Nature remains neutral with regard to jurisdictional claims in published maps and institutional affiliations. 